\title{
Avaliação da aprendizagem em química: debates necessários no contexto de (pós)
}

\section{pandemia}

\author{
Assessment of learning in chemistry: discussions required in the context of (post) pandemic \\ Evaluación del aprendizaje químico: debates requeridos en el contexto de (post) pandémicas
}

Recebido: 11/07/2021 | Revisado: 18/07/2021 | Aceito: 22/07/2021 | Publicado: 31/07/2021

\author{
Isabela Vieira da Silva \\ ORCID: https://orcid.org/0000-0001-8413-8987 \\ Universidade Federal de Juiz de Fora, Brasil \\ E-mail: isabelavdsilva@gmail.com \\ Andréia Francisco Afonso \\ ORCID: https://orcid.org/0000-0002-0107-2490 \\ Universidade Federal de Juiz de Fora, Brasil \\ E-mail: andreia.afonso@ufjf.edu.br
}

\begin{abstract}
Resumo
A avaliação da aprendizagem tem um papel importante no processo educativo, pois vai além da verificação dos erros cometidos pelos estudantes, das notas e da promoção para um nível ou série escolar mais avançada. Ela pode contribuir na identificação dos pontos que precisam ser revistos, tanto pelos estudantes, durante os estudos, quanto pelos professores, durante o (re)planejamento das aulas, de modo que o desenvolvimento do processo de ensino e aprendizagem traga benefícios para todos. Dessa forma, por considerar todo o processo, a avaliação deve ser realizada ao longo do ano letivo sob diferentes formas, e não ficar restrita a um momento pontual. Ela deve ser planejada e elaborada atentamente, especialmente durante o Ensino Remoto Emergencial (ERE), momento em que surgem dúvidas, tais como: Que tipo de avaliação é possível realizar de forma remota? Quais instrumentos são os mais adequados? Como é possível ter o controle sobre a "cola"? Como avaliar no pós-pandemia? Para promover a reflexão e o debate sobre essas questões, direcionadas ao processo avaliativo nas aulas de Química no Ensino Médio, destinamos este artigo. Espera-se também que as propostas de avaliação indicadas no texto possam contribuir com a prática avaliativa dos professores de Química atuantes na Educação Básica.

Palavras-chave: Avaliação da aprendizagem; Ensino remoto emergencial; Ensino de Química; Ensino médio; Práticas avaliativas.

Abstract

Learning assessment has an important role in the educational process, it goes beyond checking students' mistakes, grades, and promotion to a higher grade level or grade. It can contribute to the identification of points that need to be reviewed, both by students, during studies, and by teachers, during the (re)planning of classes, so that the development of the teaching and learning process brings benefits to everyone. In this way, considering the entire process, the assessment must be carried out throughout the school year in different ways, and not restricted to a specific time. It must be carefully planned and elaborated, especially during emergency remote teaching, when questions arise, such as: What type of assessment is possible to carry out remotely? Which instruments are the most suitable? How is it possible to have control over the cheating? How to assess post-pandemic? In order to promote reflection and debate on these issues, aimed at the evaluation process in Chemistry classes in High School, we intended this article. It is also expected that the evaluation proposals indicated in the text can contribute to the evaluation practice of Chemistry teachers working in Basic Education.
\end{abstract}

Keywords: Learning evaluation; Emergency remote teaching; Chemistry teaching; High school; Evaluation practices.

\section{Resumen}

La evaluación del aprendizaje tiene un papel importante en el proceso educativo, va más allá de verificar los errores, las calificaciones y la promoción de los estudiantes a un nivel o grado superior. Puede contribuir a la identificación de puntos que necesitan ser revisados, tanto por los estudiantes, durante los estudios, como por los docentes, durante la (re) planificación de clases, para que el desarrollo del proceso de enseñanza y aprendizaje beneficie a todos. Así, considerando todo el proceso, la evaluación debe realizarse a lo largo del curso escolar de diferentes formas, y no restringirse a una momento puntual. Debe planificarse y elaborarse cuidadosamente, especialmente durante la enseñanza remota de emergencia, cuando surgen preguntas, tales como: ¿Qué tipo de evaluación es posible realizar de forma remota? ¿Qué instrumentos son los más adecuados? ¿Cómo se puede controlar el pegamento? ¿Cómo evaluar la pospandémica? Con el fin de promover la reflexión y el debate sobre estos temas, orientados al proceso de evaluación en las clases de química de secundaria, creamos este artículo. También se espera que las propuestas de 
evaluación indicadas en el texto puedan contribuir a la práctica evaluativa de los profesores de Química que trabajan en Educación Básica.

Palabras clave: Evaluación del aprendizaje; Enseñanza remota de emergência; Enseñanza de la química; Escuela secundaria; Prácticas de evaluación.

\section{Um Novo Rumo para a Educação}

Este artigo foi construído no contexto de enfrentamento da pandemia decorrente do vírus SARS-CoV-2, popularmente conhecido como o "novo coronavírus", que teve início em 2019. Esse vírus é o causador da COVID 19, uma síndrome respiratória aguda grave, tipo 2, que pode levar o indivíduo infectado à morte. Seu meio de transmissão se dá de pessoa para pessoas através das gotículas que saem do nariz e/ou da boca quando indivíduos infectados falam, tossem ou espirram (World Health Organization, 2020) e quando estes tocam objetos e/ou superfícies contaminadas.

Diante dessa situação, medidas tiveram que ser tomadas para diminuir a propagação da doença ou, pelo menos, retardá-la. Além de manter a higiene individual, lavando as mãos regularmente com água e sabão, ou higienizando-as com álcool gel a 70\%, a Organização Mundial da Saúde (OMS) recomenda às pessoas que evitem aglomerações, mantendo o distanciamento físico, pois este é o modo mais eficaz de diminuir a disseminação do novo coronavírus (Díaz-Castrillón \& Toro-Montoya, 2020).

Sem o cumprimento das medidas necessárias para controle de proliferação do vírus, o número de pessoas infectadas pode aumentar a cada dia, acarretando sobrecarga dos sistemas de saúde (Díaz-Castrillón \& Toro-Montoya, 2020), uma vez que não há leitos e aparelhos que possibilitem a ventilação pulmonar em quantidade suficiente para atender um grande número da população que os necessitarem em um mesmo intervalo de tempo.

Nesse contexto, para acatar as recomendações da OMS, do Ministério da Saúde e dos cientistas e pesquisadores da área da saúde, o Brasil implementou algumas medidas e as atividades presenciais, consideradas não essenciais, foram suspensas, prosseguindo remotamente. Entre essas atividades foram incluídas aquelas relacionadas à área da Educação que adotou um sistema de ensino online, para dar continuidade ao ano letivo de 2020, prosseguindo em 2021.

Com esse sistema de ensino online, as escolas, faculdades e universidades tiveram que se reinventar para promoverem aulas com qualidade para seus alunos, preocupadas não só com o ensino e com a aprendizagem, mas também com as formas de avaliar o conhecimento construído pelos estudantes por meio da utilização dos diferentes recursos digitais. Apesar dessas tecnologias serem acessíveis há algum tempo, "ninguém, nem mesmo os professores que já adotavam ambientes online nas suas práticas, imaginava que seria necessária uma mudança tão rápida e emergencial, de forma quase obrigatória, devido à expansão da COVID 19” (Moreira et al., 2020, p. 352).

Nesse contexto, a avaliação da aprendizagem, que por ter um papel importante no processo educativo, gerou dúvidas e questionamentos por parte dos professores e gestores, tais como: Que tipo de avaliação é possível realizar de forma remota? Quais instrumentos são os mais adequados? Como é possível ter o controle sobre a cola? Como avaliar no pós-pandemia?

Assim, o objetivo deste artigo é promover a reflexão e o debate sobre essas questões direcionadas ao processo avaliativo nas aulas de Química no Ensino Médio no contexto do Ensino Remoto Emergencial (ERE) e indicar propostas que possam contribuir com a prática avaliativa desses professores atuantes na Educação Básica, no contexto do ensino online e também nas aulas presenciais, quando essas forem retomadas. No entanto, primeiramente, consideramos ser importante a compreensão do que seja o ato de avaliar. Por isso, a próxima seção trará uma discussão sobre a avaliação da aprendizagem.

\section{A Avaliação da Aprendizagem: atribuindo significado a ela}

A palavra avaliação pode ser definida como: "1. Ato ou efeito de avaliar (-se). 2. Apreciação, cômputo ou estimação da qualidade de algo ou da competência de alguém. 3. Determinação do preço justo de qualquer coisa alienável. 4. Valor de 
bens, determinado por avaliadores" (Michaelis, nd). A partir dessas definições, podemos inferir que a avaliação vai além do contexto escolar, ou seja, é uma ação que não fica restrita ao ambiente educacional, uma vez que ela faz parte de nossas inúmeras atividades diárias, visto que estamos a todo instante avaliando nossas ações para elaborar e direcionar decisões.

Mas, na sala de aula, a avaliação também pode ser utilizada para a elaboração e direcionamento de decisões por parte dos professores e alunos, pois a prática avaliativa possibilita a obtenção de dados referentes à aprendizagem dos educandos e ao ensino dos educadores, permitindo a identificação da necessidade de um acompanhamento mais próximo sobre o que e como se aprende.

Assim, "o professor, na medida em que está atento ao andamento dos seus alunos, poderá, através da avaliação da aprendizagem, verificar o quanto o seu trabalho está sendo eficiente e que desvios está tendo" (Luckesi, 2011a, p. 117) e a partir disto, caso julgue necessário, poderá replanejar suas aulas. Já o estudante poderá ter "consciência do seu limite e das necessidades de avanço. Além disso, os resultados manifestados por meio dos instrumentos de avaliação poderão auxiliar o aluno num processo de automotivação, na medida em que lhes fornece consciência dos níveis obtidos de aprendizagem" (Luckesi, 2011a, p. 117).

Além do nível de aprendizagem citado por Luckesi (2011a), o docente pode verificar o estágio do desenvolvimento cognitivo em que o estudante se encontra. O desenvolvimento cognitivo se dá conforme o estudante avança nos diferentes estágios organizados "numa hierarquia de complexidade e dependência (categorias), do mais simples ao mais complexo" (Ferraz \& Belhot, 2010, p. 422), por meio da Taxonomia de Bloom Revisada. Esses estágios estão relacionados com os objetivos de aprendizagem (Krathwohl, 2002).

A Figura 1 apresenta os seis estágios - dos níveis cognitivos mais fundamentais, como "lembrar", a níveis cognitivos mais avançados, como "criar".

Figura 1 - Categorias dos processos cognitivos da Taxonomia de Bloom Revisada.

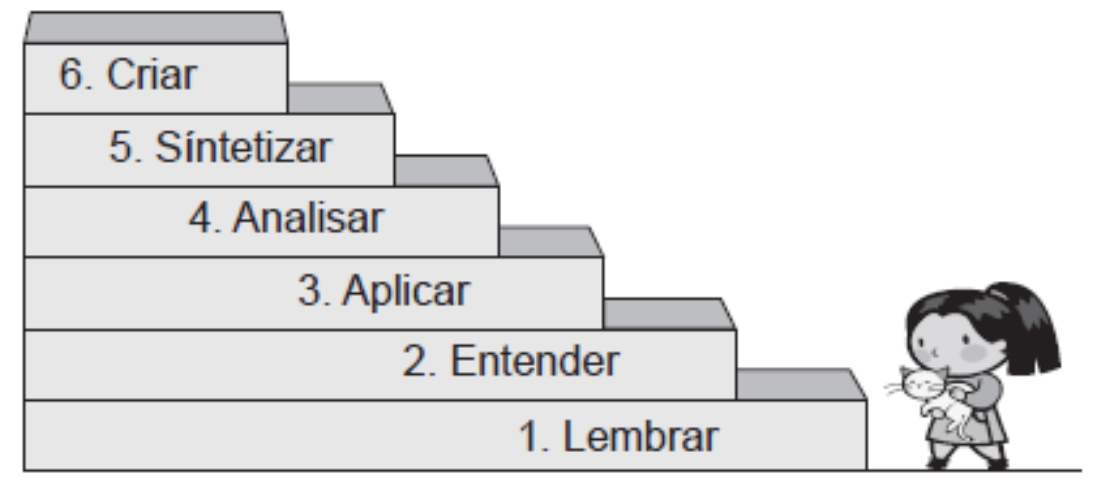

Fonte: Ferraz e Belhot (2010, p. 427).

Já o Quadro 1 explica cada um desses seis estágios e apresenta os possíveis verbos relacionados a eles.

Quadro 1 - Aspectos de cada categoria do processo cognitivo na Taxonomia de Bloom Revisada.

1. Lembrar: Relacionado a reconhecer e reproduzir ideias e conteúdos. Reconhecer requer distinguir e selecionar uma determinada informação e reproduzir ou recordar está mais relacionado à busca por uma informação relevante memorizada. Representado pelos seguintes verbos no gerúndio: Reconhecendo e Reproduzindo.

2. Entender: Relacionado a estabelecer uma conexão entre o novo e o conhecimento previamente adquirido. A informação é entendida quando o aprendiz consegue reproduzi-la com suas "próprias palavras". Representado pelos seguintes verbos no gerúndio: Interpretando, Exemplificando, Classificando, Resumindo, Inferindo, Comparando e Explicando. 
3. Aplicar: Relacionado a executar ou usar um procedimento numa situação específica e pode também abordar a aplicação de um conhecimento numa situação nova. Representado pelos seguintes verbos no gerúndio: Executando e Implementando.

4. Analisar: Relacionado a dividir a informação em partes relevantes e irrelevantes, importantes e menos importantes e entender a inter-relação existente entre as partes. Representado pelos seguintes verbos no gerúndio: Diferenciando, Organizando, Atribuindo e Concluindo.

5. Avaliar: Relacionado a realizar julgamentos baseados em critérios e padrões qualitativos e quantitativos ou de eficiência e eficácia. Representado pelos seguintes verbos no gerúndio: Checando e Criticando.

6. Criar: Significa colocar elementos junto com o objetivo de criar uma nova visão, uma nova solução, estrutura ou modelo utilizando conhecimentos e habilidades previamente adquiridos. Envolve o desenvolvimento de ideias novas e originais, produtos e métodos por meio da percepção da interdisciplinaridade e da interdependência de conceitos. Representado pelos seguintes verbos no gerúndio: Generalizando, Planejando e Produzindo.

Fonte: Ferraz e Belhot (2010, p. 429).

Dessa forma, a Taxonomia de Bloom Revisada "não é apenas um esquema para classificação, mas uma possibilidade de organização hierárquica dos processos cognitivos de acordo com níveis de complexidade e objetivos do desenvolvimento cognitivo desejado e planejado" (Paixão \& Pinto, 2019, pp. 593-594). À vista disso, ela pode auxiliar o professor durante o planejamento da avaliação, uma vez que o objetivo proposto para ela deve estar de acordo com o desenvolvimento cognitivo esperado.

Portanto, estando associada ao desenvolvimento cognitivo dos educandos, a avaliação da aprendizagem não pode ter seu foco centrado somente na verificação de acertos e erros dos estudantes e, consequentemente, na atribuição de valores, que são as notas. Essas, além de não revelarem satisfatoriamente o que o aluno pensa, não oportunizam espaços para discussão e elucidação de suas ideias (Hoffmann, 2014), pois são tratadas e operadas como se não tivessem relação com o processo de aprendizagem. Desta maneira, elas não contribuem para identificar e revelar aspectos que precisam ser melhorados no processo de ensino e aprendizagem. Assim, “as notas escolares, como vêm sendo praticadas em nossas escolas, não nos ajudam a realizar o sonho, a esperança e o desejo da democratização do ensino. Ao contrário, camuflam a realidade para que não enxerguemos os seus limitados processos e resultados" (Luckesi, 2014, p. 17).

A cultura da atribuição de notas pode estar associada ao significado atribuído à palavra avaliação, que em latim avalere é ter ou dar valor (Luckesi, 2011a). A consequência disto, é a supervalorização dos exames que são classificatórios e excludentes, e não da avaliação da aprendizagem de fato, que deve ser inclusiva, acolhendo todos os alunos durante o desenvolvimento de suas aprendizagens.

Entende-se que por ser classificatório, o exame quando utilizado na sala de aula, é seletivo. O problema é que "a seletividade suprime a necessidade e a possibilidade de futuros investimentos nos excluídos" (Luckesi, 2011b, p. 199). Contudo, apesar de sua característica seletiva, o exame é a forma mais antiga utilizada pelos professores para "avaliar" seus estudantes, e se mantém no nosso atual sistema de ensino (Chueiri, 2008; Luckesi, 2011a; Perrenoud, 2007). Ele é eficiente para constatar o conhecimento pontual do aluno que, muitas vezes, está centrado na memorização e na reprodução, e não na aprendizagem.

Desta forma, na escola, quando se toma o exame para avaliar a aprendizagem, assume-se que a avaliação é “eminentemente técnica, consistindo basicamente em testes de verificação, mensuração e quantificação de resultados” (Dias Sobrinho, 2003, p. 17). Nesse sentido, é importante destacar que “verificações, constatações e medidas são praticadas há alguns séculos e, ainda que cumpram bem alguns objetivos, não são suficientes para a compreensão de uma realidade tão 
complexa como a educação e, se exclusivos, tampouco são instrumentos capazes de levar a grandes transformações pedagógicas. [...] O que é criticável é seu uso fechado e isolado" (Dias Sobrinho, 2008, p. 202).

Embora existam críticas, os professores ainda praticam "muito mais exames escolares do que avaliação da aprendizagem" (Luckesi, 2011a, p. 29) não por um desvio ético e de conduta, mas sim por terem sido eles a única forma de avaliação pela qual passaram durante o processo de escolarização, ou seja, "fomos examinados, agora examinamos" (Luckesi, 2011a, p. 30). Talvez, se houvesse mais espaço, durante a formação inicial e continuada, para refletir e discutir sobre avaliação, os docentes poderiam planejar e agir de maneira diferente, seguindo as finalidades que são próprias à avaliação da aprendizagem.

E aliado ao exame, e ao que ele representa, está a "cola", que para Luckesi (2011b, p. 415)

[...] é estimulada pela inserção dos exames escolares na sala de aula e, ademais, pela crença de que as notas correspondem efetivamente ao sucesso do educando, e não à aprendizagem propriamente dita. A "cola", ao garantir ao educando uma boa nota, dá ares de verdade ao que constitui uma mentira. Parece que ele aprendeu, porque respondeu às questões com correção, mas, de fato, não houve aprendizado. Simplesmente ele tem notas, mas não conhecimentos e habilidades.

Com isso, ao utilizá-la o estudante priva o professor de compreender suas reais dificuldades e o que ele não aprendeu, impossibilitando-o de ser ajudado e, consequentemente, gerando maiores dificuldades de aprendizagens, que não permitem o seu avanço durante a construção do conhecimento (Luckesi, 2011b).

A seguir, apresentamos um quadro presente no trabalho de Silva e Afonso (2020), no qual há um comparativo entre as características das avaliações e exames segundo Luckesi (2011b), que pode auxiliar na compreensão desses dois termos.

Quadro 2 - Características que diferenciam as avaliações dos exames.

\begin{tabular}{|c|c|}
\hline AVALIAÇ̃̃o & EXAME \\
\hline Voltada para o futuro & Voltado para o passado \\
\hline Busca soluções para as dificuldades encontradas & Permanece aprisionado no problema \\
\hline Centrada no processo e no produto, ao mesmo tempo & Centrado no produto final \\
\hline Insere a complexidade & Simplifica a realidade \\
\hline Não é pontual & É pontual \\
\hline É diagnóstica: inclusiva, democrática, dialógica & É classificatório: seletivo, antidemocrático, \\
& autoritário. \\
\hline
\end{tabular}

Fonte: Silva \& Afonso (2020, p. 336).

A avaliação, sendo inclusiva, implica na "concepção de que ninguém pode ou deve permanecer sem aprender [...] Caso o estudante manifeste não ter aprendido, é convidado a 'entrar na aprendizagem' e é auxiliado para que ela ocorra" (Luckesi, 2011b, p. 199).

Diante do que foi exposto até o momento, neste artigo, assumimos que a função central do ato de avaliar é investigar e acompanhar o processo de ensino e aprendizagem e "subsidiar soluções para os impasses diagnosticados, a fim de chegar de modo satisfatório aos resultados desejados" (Luckesi, 2011b, p. 186).

Esses resultados desejados se referem não só a aprendizagem, mas também ao ensino. Assim, entendemos a avaliação da aprendizagem como um processo e não como um instrumento utilizado para promover a disciplina dos estudantes em sala e para puni-los. Enquanto instrumento de punição e controle, ela pouco contribui para a construção do conhecimento do estudante, já que atribui somente a este a responsabilidade pelo seu desempenho, o que destoa da concepção que temos sobre a avaliação da aprendizagem, especialmente nas aulas de Química, para as quais, este artigo está direcionado. 


\section{A avaliação da Aprendizagem de Química Durante o Ensino Remoto Emergencial}

A Química é considerada, por alguns estudantes, como uma disciplina de difícil aprendizagem. Essa percepção pode se dar pelo fato dela abordar conceitos que devem ser compreendidos a nível microscópico, ou seja, aquele que não pode ser visto. Além disso, alguns conteúdos envolvem cálculos matemáticos, que também podem não ter sido apreendidos pelos alunos. Por isso, Benedetti Filho et al. (2020, p. 581), ao citarem Oliveira, apontam que

[...] um dos fatores que eventualmente geram desinteresse pela Química é o distanciamento entre o conteúdo apresentado pelo professor e a realidade cotidiana dos estudantes, de modo que, ao longo do processo de ensino e aprendizagem, priorizam-se a memorização de leis científicas e resoluções matemáticas, estigmatizando a Química como ciência exata e em cujo contexto do ensino os professores acabam não priorizando a aplicação e importância dessa ciência no dia-a-dia dos estudantes.

Assim, para proporcionar ambientes de aprendizagens diferentes desse contexto, "é necessário promover práticas pedagógico-didáticas ativas e construtivistas que sustentem um conhecimento coletivo e uma aprendizagem colaborativa" (Moreira et al., 2020, p. 355), proporcionando ao aluno ser mais ativo no processo de construção do conhecimento.

Vale destacar as inúmeras práticas de professores de Química do Ensino Médio que se voltam a esse objetivo. Há inúmeros relatos publicados em revistas científicas e em Anais de eventos descrevendo a aplicação de metodologias diferenciadas, criação de recursos didáticos, desenvolvimento de experimentos, entre tantas outras experiências educativas voltadas à aprendizagem e ao ensino.

Mas, quando se volta à prática avaliativa dos professores de Química, constata-se pouco avanço na forma em que ela é compreendida e desenvolvida nas salas de aula, ocorrendo, majoritariamente, tão somente os exames, separados do processo de ensino e aprendizagem. Atualmente, o Ensino Remoto Emergencial tem mostrado que essa prática avaliativa precisa ser adaptada e não pode mais ser pensada e praticada da maneira como vinha sendo desenvolvida, ou seja, como eram nas aulas presenciais, com uma valorização exacerbada da memorização e da nota em detrimento da aprendizagem. Reconhece-se que a avaliação da aprendizagem de Química, neste contexto, tornou-se desafiadora, mas necessária, considerando todas as finalidades, já mencionadas anteriormente, que ela possui.

Durante esse período em que as aulas não se dão de forma presencial, espera-se que a avaliação de Química deixe de ser uma ação mecânica da prática educativa, assim como é a "aprendizagem" por meio da memorização, e se transforme em algo refletido, planejado e relacionado ao contexto em que se dá o ensino e a aprendizagem. Para isso, segundo Calado et al. (2017, p. 3):

O docente precisa realizar as mediações pedagógicas necessárias constantemente, pois o avaliar online deve caminhar entrelaçado com a interatividade e a mediação. A mediação proporciona ao docente um olhar contínuo das construções discentes, dos progressos e dificuldades, e como tal, favorece as regulações das aprendizagens em curso, fazendo com que o educando seja estimulado às contínuas elaborações e reelaborações colaborativas do saber.

Assim, para que o processo avaliativo se concretize durante o Ensino Remoto Emergencial é importante que o professor de Química proponha ações que promovam não só a interatividade e a mediação (Calado et al., 2017), como também a participação, o diálogo entre aluno-aluno e professor-alunos, a percepção da evolução da aprendizagem e a efetividade do ensino.

Todas essas ações possibilitam a escolha e a elaboração dos instrumentos avaliativos de forma mais efetiva, o que é fundamental, pois do contrário, se não forem rigorosamente selecionados e elaborados de modo que não mostrem a real aprendizagem dos alunos, estes não serão ferramentas úteis para a avaliação da aprendizagem, principalmente no contexto de Ensino Remoto Emergencial (ERE). 
Entretanto, diante das formas como o ERE se dá pode ser um desafio para o professor promover todas as ações indicadas durante o processo avaliativo. O ERE vem acontecendo por meio das aulas síncronas com a utilização de plataformas de webconferência, porém, há pouca, ou nenhuma, interação entre alunos-alunos e alunos-professor, já que o diálogo fica muito restrito por diferentes motivos: influência da conexão da internet, timidez, etc (Cunha et al., 2020). Assim, os estudantes, majoritariamente, mantêm suas câmeras desligadas e interagem pouco no chat, o que dificulta a mediação.

Algumas aulas são ainda disponibilizadas nas plataformas digitais, como o Google Classroom e YouTube, gravadas em vídeo e/ou televisionadas em canais de televisão. Nesses vídeos, quem leciona, muitas vezes, não são os professores dos alunos que as assistem (Cunha et al., 2020). Além da ausência do contato físico, que é proporcionado nas interações que acontecem em sala de aula, o professor não tem a possibilidade de ter o contato visual com seus alunos por meio do qual é possível perceber indícios de dificuldade na compreensão dos conteúdos abordados.

Logo, a avaliação da aprendizagem, enquanto acompanhamento da construção do conhecimento, fica restrita aos registros enviados pelos estudantes na forma de atividades e provas. Assim, pensando otimizar a avaliação da aprendizagem durante o Ensino Remoto Emergencial, apresentaremos exemplos de instrumentos avaliativos com a intenção de orientar as práticas avaliativas dos professores de Química do Ensino Médio. No entanto, convidamos professores de outras disciplinas a analisá-los e adaptá-los às suas aulas.

É importante destacar que não se traz modelos prontos, pois em se tratando de avaliação da aprendizagem, eles devem ser elaborados ou adaptados de acordo com o contexto de cada turma, sem perguntas ambíguas, "sem pegadinhas" para que de fato representem a aprendizagem dos alunos.

\section{Instrumentos que Podem ser Utilizados na Avaliação da Aprendizagem de Química}

Ao se indicar e discutir propostas de instrumentos avaliativos para as aulas de Química, queremos deixar claro que não indicamos uma melhor forma de coletar dados sobre a aprendizagem dos estudantes, nem que instrumentos avaliativos utilizados até o momento devem ser banidos. Apontamos caminhos que podem ser utilizados para melhor avaliar a aprendizagem dos estudantes, lembrando que para cada turma a quem o instrumento se direciona, deve haver adaptações por parte dos professores. Além disso, não nos propomos aqui a discutir sobre todos os diferentes instrumentos avaliativos nem a esgotar o assunto, mas sim apresentar algumas possibilidades de como podemos avaliar mais e examinar menos nossos estudantes.

Assim, consideramos importante começar pelo instrumento avaliativo mais difundido nas salas de aula do ensino médio - a prova -, para que compreendamos que ela não precisa ser abandonada, mas sim reelaborada e replanejada. Em seguida, trataremos e analisaremos outros instrumentos úteis e que já estão nas aulas de Química

Para a indicação das propostas, apoia-se em Luckesi (2011b, p. 297), que afirma:

[...] para realizarmos uma prática avaliativa, necessitamos de dados da realidade e, para obtê-los, necessitamos de instrumentos que ampliem nossa capacidade de observação da realidade. Importa ter presente que todos os instrumentos de coleta de dados para a avaliação da aprendizagem são úteis, desde que sejam adequados aos objetivos da avaliação, isto é, adequados às necessidades e ao objeto da ação avaliativa.

\subsection{Provas como instrumentos avaliativos a favor do aluno e da aprendizagem}

A partir das ideias construídas ao longo deste artigo e da concepção e finalidades atribuídas à avaliação da aprendizagem, as provas podem ser bons instrumentos de coleta de dados sobre a aprendizagem, contudo, é preciso que ela seja encarada para além da atribuição de notas, a partir de uma mudança de pensamento e atitude. Essa mudança envolve entre outras-ações, elaborar ou escolher questões que permitam investigar a construção do conhecimento químico e não apenas a 
memorização de fórmulas, nomes e estruturas. Também é necessário que se evite enunciados que gerem ambiguidades e "pegadinhas" (Moretto, 2005), pois estas últimas, levam a verificar apenas a atenção e capacidade do aluno em reconhecê-las e não de fato a sua aprendizagem.

Quando as provas envolvem questões de múltipla escolha, sugerimos que cada alternativa contenha os possíveis caminhos cognitivos, a partir dos níveis da Taxonomia de Bloom Revisada, que possam ser percorridos pelos estudantes. Assim, as alternativas erradas indicam o que precisa ser retomado no ensino e na aprendizagem.

\subsection{Experimento como um instrumento avaliativo que promove a autonomia dos estudantes}

Como consideramos importante que os instrumentos avaliativos promovam a autonomia dos estudantes, acreditamos ser a experimentação um recurso a ser utilizado. Mas, para que a autonomia seja desenvolvida durante o Ensino Remoto Emergencial, o professor deve propor experimentos que os alunos possam realizar em suas residências (Sales, 2020), com materiais de fácil acesso e que não ofereçam risco à segurança física e à saúde.

Durante a realização do experimento é interessante que o estudante grave um vídeo, ou registre em fotos cada etapa da atividade, explicando o que foi feito, suas observações e a relação com os conceitos estudados. Suas explicações também podem se dar na forma de esquemas, desenhos, mapas conceituais, entre outros, descrevendo o que acreditam ter acontecido.

Nesse formato, indicamos ao professor que não trabalhe com roteiros, uma vez que estes se restringem a uma sequência de ações que devem ser executadas de forma mecanizada e pouco, ou nada, crítica. Cabe propor uma discussão, momento em que o docente pode fornecer um feedback aos alunos para que consigam perceber seus avanços, dificuldades e possíveis erros, de modo a fazê-los progredir, uma vez que "o docente precisa contribuir para [...] a devida mediação pedagógica online e avaliação de maneira conjunta" (Araujo \& Abranches, 2019, p. 4).

Vaz et al. (2021, p. 229) informam que o feedback, "na perspectiva formativa da avaliação, consiste em toda informação que tem por finalidade guiar o estudante em três perspectivas: identificar o que está errado, compreender o que falta fazer ou corrigir, e como fazer para alcançar o esperado". Após o feedback, o docente pode oferecer a oportunidade aos alunos de corrigirem, complementarem ou reelaborarem a atividade, enviando-a novamente.

Trazemos dois exemplos de experimento por meio dos quais podem ser abordadas as propriedades coligativas, que uma das autoras elaborou, baseada nos trabalhos de Barros e Magalhães (2013), Vieira et al. (2007) e no segundo volume do livro didático Química cidadã (Santos \& Mol, 2016). Ele foi aplicado em uma turma do $2^{\circ}$ ano do Ensino Médio, em uma aula presencial.

Primeiro experimento:

1) Fazer uma solução salgada: Em um copo de água filtrada (150 a 200mL), adicione uma colher e meia de sal $(\mathrm{NaCl})$ (utilizar colher de sopa para a medida). Coloque essa solução salgada em um copo plástico.

2) Encha um outro copo plástico com a mesma quantidade de água filtrada (150 a 200mL). Lembre-se de fazer uma marcação para saber qual é referente a água salgada e qual é referente a água filtrada.

3) Leve os dois copos plásticos ao congelador ao mesmo tempo. Após 35 - 40 minutos, abra o congelador e registre as suas observações e tente explicá-las a partir de conteúdos químicos.

Segundo experimento:

1) Coloque aproximadamente 5 uvas-passas em um recipiente com água suficiente para cobri-las.

2) Feche o recipiente e observe de tempos em tempos (1, 8, 24 e 48 horas) o que acontece, comparando com uma uva-passa que não tenha sido colocada no recipiente (controle). Ao final, tente explicar o que ocorreu. 
A partir das respostas apresentadas pelos alunos e a discussão promovida pelo professor, será possível verificar se os estudantes compreenderam o que aconteceu nos experimentos, se conseguiram inferir sobre as possíveis causas que levaram as diferenças observadas, se utilizam a linguagem científica de forma adequada e se conseguem relacionar o conteúdo químico (no caso, as propriedades coligativas) com o cotidiano.

Caso algum desses pontos não seja alcançado, o professor pode, a partir de perguntas, encaminhar o pensamento dos estudantes a fim de que eles consigam estabelecer relações e construam ou desenvolvam o seu conhecimento a respeito das propriedades coligativas, até alcançarem os objetivos de aprendizagem planejados pelo professor para aquele conteúdo ou para aquela aula. Assim, será possível promover ações e intervenções que possam oportunizar o avanço da aprendizagem, aliando ensino, aprendizagem e avaliação.

\subsection{Situações-problema como um instrumento avaliativo que promove a investigação}

Um outro instrumento que pode auxiliar os professores na coleta de dados sobre a aprendizagem dos alunos são as situações-problema, as quais os estudantes precisam encontrar respostas para solucioná-las, utilizando para isso, o conhecimento adquirido e/ou em construção e a pesquisa. Segundo Sordi (2001), é esperado que ocorra "a mobilização dos saberes trabalhados e que, por sua crescente complexidade, exijam a interlocução do aluno com os colegas, com a realidade, com demais professores ou especialistas, outras fontes escritas ou orais" (p. 179).

Por meio das situações-problema, o professor pode ter a chance de discutir sobre as fontes de pesquisa que são confiáveis, uma vez que as crianças e jovens copiam as informações de diferentes sites, sem verificar a veracidade das mesmas, confiando que todas são verdadeiras.

Assim, a partir do trabalho com situações-problemas o processo avaliativo pode se constituir da seguinte maneira:

Avaliação Diagnóstica: na qual o professor precisa analisar os conhecimentos prévios dos alunos, facilitando o desenvolvimento cognitivo do aprendiz;

Avaliação Formativa: durante a resolução da SP [situação-problema], o professor observa todo o processo dos alunos na busca pela resolução do problema, intervindo quando julgar necessário;

Avaliação Somativa: realizada ao final do processo, solicitada ao discente, em forma de relatório [ou outra forma de apresentação] (Souza Lima \& Silva, 2013, p. 3).

A partir desses instrumentos avaliativos citados, temos certeza de que o professor, está lembrando de outros instrumentos que já utilizou ou vem utilizando. Mas, voltamos a destacar que em todos os casos, o instrumento avaliativo deve ser cuidadosamente e rigorosamente construído e utilizado, para que cumpram de fato seu objetivo que é coletar dados sobre a aprendizagem dos estudantes.

Independentemente dos instrumentos avaliativos que podem ser utilizados, cabe ao professor fazer anotações qualitativas com datas e informações, consideradas essenciais, sobre as atividades desenvolvidas pelos estudantes, pois essas podem informar sobre o percurso da aprendizagem. Ainda segundo Calado et al. (2017, p. 8), "os registros no ambiente virtual são fundamentais para que o docente tenha elementos para conhecer seu aluno, suas dificuldades, êxitos, entraves, buscando redirecionar o processo de aprendizagem".

Como forma de auxiliar essas anotações, apresentamos as rubricas que podem ser utilizadas na avaliação da aprendizagem.

\section{As Rubricas para a Avaliação da Aprendizagem}

As rubricas podem ser entendidas como uma ferramenta para a sistematização das apreciações qualitativas da aprendizagem, a partir dos instrumentos avaliativos que citamos e muitos outros que podem ser utilizados pelo professor, como 
por exemplo: seminários, debates, trabalhos em grupo, etc. Segundo Fernandes (2021, p. 4), "as rubricas deverão incluir o conjunto de critérios que se considera traduzir bem o que é desejável que os alunos aprendam e, para cada critério, um número de descrições de níveis de desempenho". Esses níveis, a serem elaborados para cada critério, quando descritos detalhadamente de forma clara e objetiva, direcionam o estudante para a autoavaliação da sua aprendizagem, e o professor, no que se refere a sua prática (Biagiotti, 2005).

Ainda sobre as rubricas, Fernandes (2021, p. 4) faz uma importante consideração dizendo que

[...]embora as rubricas nos permitam avaliar, elas são descritivas e não avaliativas por natureza. Em vez de julgar o desempenho, professores e alunos verificam qual a descrição que melhor o pode representar. Assim, antes do mais, as rubricas permitem desenvolver uma avaliação de referência criterial. E isto significa que estamos a comparar o que os alunos sabem e são capazes de fazer num dado momento com um ou mais critérios e suas descrições e não com uma média ou com um grupo, como acontece na avaliação de referência normativa [classificatória].

As rubricas podem ser a base do feedback que o professor dará ao seu aluno, sobre seus avanços e o que é preciso melhorar. "Nessa perspectiva, a avaliação desponta como um diálogo, um processo de troca, que aperfeiçoa os envolvidos no processo de ensino-aprendizagem" (Biagiotti, 2005, p. 6).

Para facilitar esse diálogo, as rubricas costumam ser apresentadas na forma de tabelas ou listas. Ao elaborá-las, em conjunto com os estudantes, conforme orientações da literatura científica, é preciso, inicialmente, que o docente defina os objetivos de aprendizagem, ou seja, os resultados que ele espera dos estudantes nas atividades propostas. A partir disto, o professor deve ir progredindo na escala de evolução da aprendizagem. Neste caso também o docente pode utilizar os níveis da Taxonomia de Bloom Revisada para auxiliá-los na construção das rubricas.

Os resultados podem ser divulgados na forma de podcasts e confrontados, para que os envolvidos percebam se possuem a mesma perspectiva para a educação. Talvez essa divergência nas perspectivas é que causa as dificuldades na aprendizagem e no ensino.

\section{Como será Feita a Avaliação da Aprendizagem no Período pós-pandemia?}

Retomando aos questionamentos iniciais e após o que foi colocado neste artigo, como avaliamos nossos alunos no Ensino Remoto Emergencial? Pelas colocações, podemos afirmar que a avaliação da aprendizagem não pode ser pontual, mas sim, um indicativo de como está o processo de desenvolvimento da aprendizagem dos estudantes para que, de posse deste diagnóstico, se possa (re)planejar o ensino e assim promover aprendizagens. Muitos instrumentos podem ser utilizados para auxiliar nesta tarefa, desde que selecionados de acordo com os objetivos do que se pretende avaliar, que devem estar muito claros para o professor.

Além disso, os recursos devem fornecer resultados que possam ser interpretados para uma tomada de decisão e não somente para atribuição de notas, como viemos discutindo ao longo deste artigo. Portanto, a avaliação deve ir além da aplicação de um instrumento avaliativo, da sua correção e retorno de uma nota para o aluno, somente para classificar alunos entre aprovados e reprovados.

E no período pós-pandemia, como será a avaliação da aprendizagem? Pelo que foi apresentado até o momento, acreditamos que poderá seguir na mesma ideia do Ensino Remoto Emergencial, contudo de maneira mais particular, pois, inicialmente, é necessário que se acolha os alunos, que conversemos sobre o momento em que passamos fora da escola para que possamos compreender como foi este período de distanciamento social e de ensino online para os eles. Após essas aulas iniciais, é fundamental que seja feita uma avaliação diagnóstica dos alunos, para compreendermos de modo mais específico o desenvolvimento de suas aprendizagens e, a partir daí, planejar as próximas aulas e ações. 
A avaliação diagnóstica consiste basicamente em constatar a aprendizagem do aluno, o que ele já aprendeu e o que ainda não foi consolidado e, por isso, normalmente, ela é utilizada no início do ano ou bimestre. Segundo Lemos e Sá (2013), com a avaliação diagnóstica, o professor "busca verificar a presença e a ausência dos conhecimentos adquiridos, além de condições de aprendizagem que funcionem como pré-requisitos para que o aluno possa iniciar a aprendizagem a partir de determinado nível” (p. 56).

Particularmente, é válido destacar que este tipo de avaliação não precisa ser algo tão formal, como uma prova, ela pode ser uma simples conversa entre professor e aluno, pois o mais importante é o diagnóstico, a intencionalidade, e não o instrumento, para que o professor possa traçar estratégias junto a direção e coordenação pedagógica da escola a fim de garantir a aprendizagem de todos. Cabe ressaltar que, como discutido anteriormente, avaliar não é sinônimo de dar notas ou classificar. Neste primeiro momento de diagnóstico, no período de retorno presencial das aulas, a preocupação e os esforços dos professores e estudantes devem estar direcionados à promoção da aprendizagem e, por isso, todos os estudantes devem ser incluídos e têm o direito de aprender.

No âmbito do ensino remoto, o diagnóstico é ainda mais importante uma vez que temos alunos que possuem tempos de aprendizagem diferentes, o que já era perceptível nas aulas presenciais. Além disso, nem todos possuem as mesmas condições de acesso às aulas (Alves, 2020; Cunha et al., 2020; Nascimento \& Santos, 2020). Assim, uma avaliação que realmente vai apontar a realidade é aquela que "leva em consideração o que estava ocorrendo antes, o que está ocorrendo agora e o que ainda pode vir a ocorrer no futuro, próximo ou distante" (Luckesi, 2011b, p. 195), considerando a "complexidade das variáveis que intervêm na produção dos resultados considerados intermediários ou finais, pois somente atuando sobre elas e reduzindo os seus efeitos é que a aprendizagem poderá vir a ser satisfatória” (Luckesi, 2011b, p. 191).

Salientamos que, ao (re)pensar o processo avaliativo visando a inclusão do aluno no processo de aprendizagem, não estamos considerando elaborar processos e instrumentos avaliativos mais fáceis e nem somente aspectos atitudinais, é necessário que estes permaneçam com rigor, seriedade a que os estudantes têm direito e que avaliem o conhecimento do estudante sobre aquele determinado conteúdo (Luckesi, 2011a, 2001b), no nosso caso, o conteúdo químico.

\section{Considerações Finais}

Diante do exposto, podemos perceber que o professor e a gestão escolar precisam compreender a complexidade e a importância da avaliação da aprendizagem, para que assim encontrem as melhores formas de avaliar neste contexto de (pós) pandemia, questionando se é realmente necessária a atribuição de notas.

Uma avaliação que se destina a contribuir com o ensino e com a aprendizagem no contexto do Ensino Remoto Emergencial, e após o mesmo, deve considerar todo o processo e não um momento pontual, e, por isso, deve ser realizada ao longo do ano letivo, tendo como objetivo a (re)orientação do ensino para o professor, ou seja, um novo olhar sobre seu planejamento, com vistas a promover a melhoria da aprendizagem dos alunos.

Por esse motivo, consideramos que é preciso uma mudança na prática avaliativa por meio da mudança na atitude do professor, no que diz respeito ao significado e função atribuídos a avaliação. Os instrumentos a serem utilizados durante este processo podem ser muitos, mas sempre ajustados a esses significados e funções.

Além disso, é necessário um olhar mais acurado para os instrumentos avaliativos, pois esses auxiliarão o professor na avaliação da aprendizagem de seus alunos, e também da sua prática pedagógica. Vale ressaltar que eles podem ainda permitir que os estudantes se autoavaliem em relação a sua aprendizagem, ou seja, suas facilidades e dificuldades, reconhecendo seus erros, e buscando meios para corrigi-los. Espera-se também que as propostas de avaliação indicadas no texto possam contribuir com a prática avaliativa dos professores de Química atuantes na Educação Básica. 
Assim, apresentamos este texto para tentar promover uma reflexão sobre o verdadeiro papel da avaliação da aprendizagem no ensino, seja ele remoto ou presencial.

\section{Referências}

Alves, L. (2020). Educação remota: entre a ilusão e a realidade. Interfaces Científicas-Educação, 8(3), 348-365.

Araújo, R. K. S., \& Abranches, S. P. (2019). Avaliação Interativa-Mediadora: uma framework para avaliar a aprendizagem na educação online. Anais do II Encontro Regional Norte-Nordeste da ABCiber, Aracaju. https://eventos.set.edu.br/abciber/article/view/13225/5050.

Barros, H. L. C., \& Magalhães, W. F. (2013). Efeito Crioscópico: Experimentos Simples e Aspectos Atômico-Moleculares. Química Nova na Escola, 35(1), 41-47.

Benedetti Filho, E., Cavagis, A. D. M., \& Benedetti, L. P. S. (2020). Jogo didático de cartas para revisões conceituais no ensino de Química Orgânica. Experiências em Ensino de Ciências, 15(3), 580-590.

Biagiotti, L. C. M. (2005). Conhecendo e Aplicando Rubricas em Avaliações. Anais do $12^{\circ}$ Congresso Internacional ABED de Educação a Distância, Florianópolis. http://www.abed.org.br/congresso2005/por/pdf/007tcf5.pdf.

Calado, E. F. N., Araújo, R. K. S., Silva, A. P. T. B., Mota, A. C., \& Silva, I. M. M. (2017). Processo de avaliação da aprendizagem na educação online: entre concepções e práticas docentes. Anais do $23^{\circ}$ Congresso Internacional ABED de Educação a Distância, Foz do Iguaçu. http://www.abed.org.br/congresso2017/trabalhos/pdf/225.pdf.

Chueiri, M. S. F. (2008). Concepções sobre a avaliação escolar. Estudos em Avaliação Educacional, 19(39), 49-64.

Cunha, L. F. F., Silva, A. S., \& Silva, A. P. (2020). O ensino remoto no Brasil em tempos de pandemia: diálogos acerca da qualidade e do direito e acesso à educação. Revista Com Censo: Estudos Educacionais do Distrito Federal, Brasília, 7(3), 27-37.

Dias Sobrinho, J. (2008). Avaliação educativa: produção de sentidos com valor de formação. Avaliação: Revista da Avaliação da Educação Superior, Campinas, 13, 193-207.

Dias Sobrinho, J. (2003). Avaliação: políticas e reformas da Educação Superior. São Paulo: Cortez.

Díaz-Castrillón, F. J. \& Toro-Montoya, A. I. (2020). SARS-CoV-2/COVID-19: el virus, la enfermedad y la pandemia. Medicina \& Laboratorio, 24(3), 183205.

Fernandes, D. (2021). Rubricas de Avaliação. Folha de apoio à formação - Projeto de Monitorização, Acompanhamento e Investigação em Avaliação Pedagógica (MAIA). Ministério da Educação/Direção-Geral da Educação.

https://afc.dge.mec.pt/sites/default/files/2021-04/Folha\%205_Rubricas\%20de\%20Avalia\%C3\%A7\%C3\%A3o.pdf.

Ferraz, A. P. C. M., \& Belhot, R. V. (2010). Taxonomia de Bloom: revisão teórica e apresentação das adequações do instrumento para a definição de objetivos instrucionais. Gestão \& Produção, São Carlos, 17(2), 421-431. https://doi.org/10.1590/S0104-530X2010000200015.

Hoffmann, J. (2014). Avaliação: mito \& desafio: uma perspectiva construtivista. (44 ed.). Porto Alegre: Mediação.

Krathwohl, D. R. (2002). A revision of Bloom's taxonomy: An overview. Theory into practice, 41(4), 212-218.

Lemos, P. S., \& Sá, L. P. (2013). A avaliação da aprendizagem na concepção de professores de química do ensino médio. Revista Ensaio, Belo Horizonte, 15(3), 53-71.

Luckesi, C. C. (2011b). Avaliação da aprendizagem: componente do ato pedagógico. (1. ed.). São Paulo: Cortez.

Luckesi, C. C. (2011a). Avaliação da aprendizagem escolar: estudos e proposições. (22. ed.). São Paulo: Cortez.

Luckesi, C. C. (2014). Sobre notas escolares: distorções e possibilidades. São Paulo: Cortez.

Michaelis. (nd). Avaliação. In Dicionário Brasileiro da Língua Portuguesa. São Paulo: Editora Melhoramentos LTDA. https://michaelis.uol.com.br/modernoportugues/busca/portugues-brasileiro\%20/avalia\%C3\%A7\%C3\%A3o.

Moreira, J. A., Henriques, S., \& Barros, D. M. V. (2020). Transitando de um ensino remoto emergencial para uma educação digital em rede, em tempos de pandemia. Dialogia, 34, 351-364. https://doi.org/10.5585/Dialogia.N34.17123.

Moretto, V. P. (2005). Prova: um momento privilegiado de estudo não um acerto de contas. (6. ed.). Rio de Janeiro: DP\&A.

Nascimento, I. S., \& Santos, P. C. (2020). A normalidade da desigualdade social e da exclusão educacional no brasil. Caderno De Administração, 28(Edição E), 122-130.

Paixão, M. V., \& Pinto, L. R. (2019). Avaliação por conceito na educação profissional e tecnológica e a Taxonomia de Bloom: uma possibilidade? Debates em Educação, Maceió, 11(24), 586-599.

Perrenoud, P. (2007). Avaliação: da excelência à regulação das aprendizagens - entre duas lógicas. Tradução de Patrícia C. Ramos. (reimpressão). Porto Alegre: Artmed. 
Research, Society and Development, v. 10, n. 9, e45310918111, 2021

(CC BY 4.0) | ISSN 2525-3409 | DOI: http://dx.doi.org/10.33448/rsd-v10i9.18111

Sales, P. F. (2020). "Químiemcasa": aspectos de um processo de ensino para a aprendizagem de Química em épocas de pandemia. Research, Society and Development, 9(11), 1-19.

Santos, W., \& Mol, G. (2016). Química cidadã. (3. ed., Vol. 2). São Paulo: Editora AJS.

Silva, I. V., \& Afonso, A. F. (2020). Instrumento de Avaliação: elaboração de uma proposta por um grupo de professores de Química do Ensino Médio. In A docência e a divulgação científica no ensino de ciências. Faleiro, W., Barros, M. V., Andreata, M. A. (Orgs). Goiânia: Kelps. http://kelps.com.br/wpcontent/uploads/2020/03/a-docencia-e-a-divulgacao_ebook.pdf.

Sordi, M. R. L. (2001). Alternativas propositivas no campo da avaliação: por que não? In CASTANHO, S., CASTANHO, M. E. (Orgs). Temas e textos em metodologia do ensino superior. (6. ed.), Campinas: Papirus, (Coleção Magistério: Formação e Trabalho Pedagógico).

Souza Lima, M. V., \& Silva, S. A. (2013). O que os Licenciandos (as) em Química pensam sobre a Estratégia Didática de Resolução de Situações-Problema. Atas do IX Encontro Nacional de Pesquisa em Educação em Ciências - IX ENPEC, Águas de Lindóia, São Paulo. http://abrapecnet.org.br/atas_enpec/ixenpec/atas/resumos/R1080-1.pdf.

Vaz, R. F. N., Nasser, L., \& Lima, D. O. (2021). Avaliar para aprender: um ato de insubordinação criativa. Revista @mbienteeducação. São Paulo: Universidade Cidade de São Paulo, 14(1), 214-243.

Vieira, H. J., Figueiredo-Filho, L. C. S. \& Fatibello-Filho, O. (2007). Um experimento simples e de baixo custo para compreender a osmose. Química Nova na Escola, 26, 40-43.

World Health Organization. (2020). Doença por coronavírus (COVID-19). https://www.who.int/emergencies/diseases/novel-coronavirus-2019/question-andanswers-hub/q-a-detail/q-a-coronaviruses. 